\title{
Mushrooms bio-residues valorisation: Optimisation of ergosterol extraction using response surface methodology
}

\author{
Ana Rita Silva ${ }^{a, b}$, Taofiq Oludemi ${ }^{a}$, Cristina Costa ${ }^{c}$, Joana Barros ${ }^{c}$, \\ Inês Ferreira ${ }^{c}$, João Nunes ${ }^{c}$, Miguel A. Prieto ${ }^{d}$, Jesús Simal-Gandara ${ }^{d}$, \\ Lillian Barros $^{a, *}$, Isabel C.F.R. Ferreira ${ }^{a, *}$ \\ a Centro de Investigação de Montanha (CIMO), Instituto Politécnico de Bragança, Campus de Santa Apolónia, \\ 5300-253 Bragança, Portugal \\ b Departamento de Ciencias Farmacéuticas, Facultad de Farmacia, CIETUS-IBSAL, Universidad de Salamanca, \\ 37007 Salamanca, Spain \\ c Centre Bio R\&D Unit, Association BLC3 - Technology and Innovation Campus, Rua Nossa Senhora da Conceição, \\ n2, 3405-155 Oliveira do Hospital, Portugal \\ d Nutrition and Bromatology Group, Department of Analytical and Food Chemistry, Faculty of Science, University of \\ Vigo - Ourense Campus, Ourense, Spain
}

A R T I C L E I N F O

Article history:

Received 23 February 2020

Received in revised form 27 March

2020

Accepted 15 April 2020

Available online $\mathrm{xxx}$

\section{Keywords:}

Mushrooms

Bio-residues

Heat-assisted extraction

Ergosterol

Response surface methodology

\begin{abstract}
A B S T R A C T
The bio-residues of Pleurotus ostreatus, Agrocybe cylindracea, and Pleurotus eryingii were studied as sustainable sources of ergosterol. Its extraction was performed by a heat-assisted extraction technique and optimised using response surface methodology. The responses were: extraction yield of the residual material (R) from the mushroom bio-residues dried weight (\%), the quantification of ergosterol in the $\mathrm{M} \mathrm{dw}(\mathrm{mg} \mathrm{E} / 100 \mathrm{~g} \mathrm{M} \mathrm{dw})$, and in the $\mathrm{R}(\mathrm{mg}$ $\mathrm{E} / \mathrm{g} \mathrm{R}$ ). The most feasible responses for industrial transference were obtained for P. ostreatus bio-residues, at the optimal conditions of $65.6 \mathrm{~min}$ at $30^{\circ} \mathrm{C}$ and $43.7 \mathrm{~min}$ at $90^{\circ} \mathrm{C}$ producing $43.72 \mathrm{mg}$ E/g R and $290.90 \mathrm{mg} \mathrm{E} / 100 \mathrm{~g} \mathrm{M}$ dw, respectively. The model satisfactorily fitted the experimental data for all responses, thus implying a good agreement between the experimental values and those predicted by the model. The study proposes a simple and efficient method to produce an ergosterol rich extract from mushroom bio-residues.
\end{abstract}

(c) 2020 Institution of Chemical Engineers. Published by Elsevier B.V. All rights reserved.

\section{Introduction}

Edible, medicinal, and wild mushrooms are the three major components of the global mushroom industry, recently accounted for US\$ 38.13 billion, and expanding at a compound annual growth rate (CAGR) of 7.9\% from 2018 to 2026 (Research and Markets, 2018; Royse et al., 2017). Europe is the key bio-economy market and holds the largest revenue share in the global mushroom industry due to the high demand for fresh and canned mushrooms in Spain, Netherlands, France, and Germany (Boin and Nunes, 2018; Research and Markets, 2018). During mushroom's processing, a large amount of bioresidues are generated: volva and the bottom part of the stems due to their tough texture, the substrate used for mushroom growth, and the specimens that do not fit the market requirements (irregular dimensions/shape/colour) (Heleno et al., 2016b; Tao et al., 2004). Depending on the size of the mushroom industry, an expressive volume (20-35\% in weight

\footnotetext{
* Corresponding authors.

E-mail addresses: lillian@ipb.pt (L. Barros), iferreira@ipb.pt (I.C.F.R. Ferreira).
} https://doi.org/10.1016/j.fbp.2020.04.005

0960-3085/@ 2020 Institution of Chemical Engineers. Published by Elsevier B.V. All rights reserved. 
of fresh mushrooms) of bio-residues is often discarded, even though their content in biomolecules are not necessarily compromised (Heleno et al., 2016b). Each person consumes approximately $5 \mathrm{~kg}$ of mushroom per year, and since mushroom production/consumption rates are expected to increase in the next years, its associated problems are likely to follow the trend (Royse et al., 2017). These high-value unexploited residues demand industries to deal with its environmental impact and managing costs (Grimm and Wösten, 2018; Leiva et al., 2015).

Recent research data demonstrates that the consumption of about $1.6-2 \mathrm{~g} / \mathrm{d}$ of sterols and stanols after a meal, preferably dissolved in a fat rich food matrix, is effective in lowering LDL cholesterol levels by 10\% (Marangoni and Poli, 2010). Edible mushrooms also contain sterols with structural similarities to phytosterols and cholesterol. Ergosterol (ergosta-5,7,22-trien$3 \beta-o l)$ is the major sterol of mushroom hyphal membranes (approx. $80 \%$ of the sterols $w / w$ ) followed by other derivatives such as ergosta-5,8,22-trien-3-ol, ergosta-7,22-dien-3-ol, ergosta-5,7-dien-3-ol, and ergosta-7-en-3-ol (fungisterol) (GilRamírez et al., 2013). Schneider et al. (Schneider et al., 2011) investigated the cholesterol lowering properties of Pleurotus ostreatus mushroom diet in humans for the first time during a placebo study. The beneficial effects on blood serum parameters were hypothetically attributed to the presence of ergosterol, linoleic acid, and ergosta-derivatives, which showed notable activity in oxygen radical absorbance capacity and cyclooxygenase inhibition assays in vitro (Schneider et al., 2011). Later, a 2014 study reported that ergosterolenriched fractions obtained from Agaricus bisporus moderately reduced cholesterol from mixed food micelles (DMMs) during gastrointestinal digestion (Gil-Ramírez et al., 2013). In the following study, the same fractions significantly reduced hepatic triglyceride levels and altered mRNA expression of cholesterol-related genes, revealing a potential effect against hepatic steatosis (Gil-Ramírez et al., 2016). Hence, due to its well-known anti-inflammatory (Ma et al., 2013; Taofiq et al., 2016c), anti-cancer (He et al., 2018; Kang et al., 2015), and anti-tyrosinase (Taofiq et al., 2016a, 2016b) activities, together with its use in new drug formulations associated with antibiotics (Tintino et al., 2017), there is an increasing interest in ergosterol. Ergosterol presence and concentration are specie dependent and influenced by many other factors (Heleno et al., 2016a; Kalač, 2009; Mattila et al., 2002). To understand the health-promoting effects of ergosterol-rich extracts obtained from mushrooms bio-residues, studies to maximise its recovery need to be conducted (Corrêa et al., 2018; López et al., 2018; Valverde et al., 2015). When studying a productive process, such as extraction, the interferences can be globally assessed by applying a mathematical modelling to optimise the interactions between experimental variables and, simultaneously, predict the most efficient conditions (Albuquerque et al., 2016; Roriz et al., 2017). The present work was developed within different interfaces (SME and scientific and technological entities), aimed at optimising ergosterol extraction from mushroom bio-residues using conventional heat assisted extraction (HAE), and evaluating the combined effects of temperature and time on the final yield using response surface methodology (RSM) (López et al., 2018; Muñiz-Márquez et al., 2019; Sarabia and Ortiz, 2009). The studied species were Pleurotus ostreatus, Pleurotus eryngii, and Agrocybe cylindraceae, three mushrooms widely consumed in the world (Boin and Nunes, 2018).

\section{Material and methods}

\subsection{Mushroom samples}

Pleurotus eryngii (PER), Agrocybe cylindraceae (ACR) and Pleurotus ostreatus (POR) mushrooms were cultivated by MicNatur (SME, Spin off of BLC3 - Oliveira do Hospital), based on controlled system, and its bio-residues (volva, the bottom part of the stems, and the specimens that do not fit the market requirements) dried in a circulation oven at $40^{\circ} \mathrm{C}$, milled to a fine powder ( $\sim 0$ mesh), vacuum packed, and stored at room temperature for further analysis.

\subsection{Standards and reagents}

Methanol and acetonitrile (HPLC grade) were purchased from Fisher Scientific (Lisbon, Portugal) and ergosterol (E6510; CAS number: 57-87-4) was acquired from Sigma-Aldrich (St. Louis, MO, USA). All other chemicals were of analytical grade and obtained from common sources. Milli- $Q^{\circledR}$ was the water utilised in all the performed assays (TGI Pure Water Systems, Greenville, SC, USA).

\subsection{Heat-assisted extraction (HAE) of ergosterol (E)}

The dried samples $(600 \mathrm{mg})$ were placed in a vial with $20 \mathrm{~mL}$ of ethanol, following a solid/liquid ratio $(\mathrm{S} / \mathrm{L})$ of $30 \mathrm{~g} / \mathrm{L}$. The vial containing the mixture was then positioned in a thermostatic water bath within a specific time interval (continuous electromagnetic stirring). The powdered samples were extracted according different time $(t)$ and temperature $(T)$ intervals, 10-150 min and $30-90^{\circ} \mathrm{C}$, respectively. The RSM design comprises 16 experimental runs with 4 centre points, previously planned and based on literature research and group experience (Heleno et al., 2016b; López et al., 2018; Vieira et al., 2017). After extraction, samples were filtered, supernatant carefully collected, and the dry weight obtained to deduce extraction yield.

\subsection{Ergosterol quantification}

Dried extracts were re-dissolved in methanol at a final concentration of $20 \mathrm{mg} / \mathrm{mL}$ and filtered through a $0.22 \mu \mathrm{m}$ nylon disposable filter. E identification and quantification was performed using a HPLC-UV equipment, an integrated system composed by a pump (Knauer, Smartline system 1000, Berlin, Germany), a degasser system (Smartline manager 5000), an auto-sampler (AS-2057 Jasco, Easton, MD, USA), and a UV detector (Knauer Smartline 2500) as previously described by Barreira et al. (2014). The separation was performed at $280 \mathrm{~nm}$ using an Inertsil 100A ODS-3 reversed-phase column (Barreira et al., 2014) and acetonitrile/methanol (70:30, v/v) as mobile phase. $E$ was quantified using a calibration curve obtained from a commercial. Data analysis was performed using Clarity 2.4 Software (DataApex).

\subsection{Response surface methodology (RSM)}

\subsubsection{Experimental design}

The RSM design was used to explore the interactions between independent $(t$ and $T)$ and dependent variables $\left(Y_{1}, Y_{2}\right.$, and $\mathrm{Y}_{3}$ ) of the experiment using a small number of combinations. The combined effect of the independent variables was studied using an orthogonal rotatable design of 5 levels coding 
the possible interactions between $t$ and $T$ (RSM mathematical model does not use values, all variables were coded), which compromises a total of 16 experimental runs. The unexpected variability of the obtained responses was reduced through experimental runs randomisation.

\subsubsection{Responses format values to present the results}

The responses were expressed in the form of three dependent variables $(\mathrm{Y}): \mathrm{Y}_{1}$, the \% of extracted material $(\mathrm{R})$; $\mathrm{Y}_{2}$, in $\mathrm{mg}$ of E obtained in the extract residue ( $\mathrm{mg} \mathrm{E} / \mathrm{g} \mathrm{R}$ ), applied to evaluate the $\mathrm{E}$ purity in the extracts; and $\mathrm{Y}_{3}$, in $\mathrm{mg}$ of $\mathrm{E}$ in $100 \mathrm{~g}$ of mushroom dry weight material (mg E/100 g M dw), used to analyse the different $\mathrm{E}$ extraction yields.

\subsubsection{Mathematical model}

To further analyse the obtained experimental values, a polynomial model including linear, quadratic and interactive effects was used:

$$
\begin{gathered}
Y=b_{0}+\sum_{i=1}^{n} b_{i} X_{i}+\sum_{\substack{i=1 \\
j>i}}^{n-1} \sum_{j=2}^{n} b_{i j} X_{i} X_{j}+\sum_{i=1}^{n} b_{i i} X_{i}^{2} \\
\end{gathered}
$$

where $Y$ was the response (dependent variable) to be modelled; $X_{i}$ and $X_{j}$, the independent variables, $b_{0}$, the constant coefficient; $b_{i}$, the coefficient of linear effect; $b_{i j}$, the coefficient of interaction effect; $b_{i i}$, the coefficients of quadratic effect; and $n$, the number of variables.

\subsection{Variable optimisation for maximum response}

To solve the non-linear problems of the predictive model, a maximised processed was performed as previously described by Albuquerque et al. (2016). Certain limitations were imposed (i.e., t lower than 0 ) to avoid variables with unnatural and unrealistic physical conditions.

\subsection{Numerical methods and statistical analysis}

As extensively described by Pinela et al. (2017, 2018), fitting procedures, coefficient estimates, and statistical calculations were performed as follows: (a) to minimise the sum of the quadratic differences between the experimental and the model-predicted values, the coefficient measurement was performed using the nonlinear least-square (quasi-Newton) method provided by the macro "Solver" of Microsoft Excel; (b) to determine the parametric confidence intervals, the coefficient significance was evaluated using 'SolverAid'. To simplify the model, the non-significant terms ( $p$-value $>0.05$ ) were dropped; and finally; (c) the following statistical assessment criteria were performed for verified the model adequacy: (i) the Fisher F-test $(\alpha=0.05)$ was used to determine whether the models describe properly the observed data; (ii) the 'SolverStat' macro assessed the parameter and model prediction uncertainties; and (iii) the proportion of variability of the dependent variable explained by the model was achieved using $R^{2}$ value (Taofiq et al., 2019).

\section{Results and discussion}

\subsection{Preliminary selection of the relevant variables and instrumental parameters to centre experimental domains before RSM application}

The selection of an adequate extraction method and optimal independent variables have gained particular relevance due to its direct interference in yield and/or quality of the extracts (Cásedas et al., 2017; Chemat et al., 2017; Khadhraoui et al., 2018). The characteristics of mushroom matrices, $E$, and ethanol, as well as the resistance of $E$ to certain ranges of $T$, make heat assisted extraction a valid methodology for $E$ extraction. Therefore, a total of 16 experimental runs were utilised to optimise the extraction of $E$ from mushroom bio-residues. HAE technique together with the 16 conditions were selected based on literature evidence, group experience attesting the efficiency of this method for E extraction, as well as the preservation of its bioactive properties when submitted to heat (Heleno et al., 2016b). The procedure consists of mixing the solid (mushroom powder) with a solvent (ethanol) followed by stirring for a certain period of $t$ at a specific $T$. It is a simple technique with low requirements in terms of equipment and costs, being easily scaled up at industrial level. For the selection of an appropriate solvent, the use of toxic or hazardous organic solvents was avoided. Together with being a more green approach when compared to benzene, cyclohexane, and dichloromethane, ethanol proved to be one of the most efficient solvents to extract $E$ $(676 \pm 3 \mathrm{mg} / 100 \mathrm{~g} \mathrm{dw}$ ) during a previous study (Heleno et al., 2016a), followed by limonene $(261 \pm 11 \mathrm{mg} / 100 \mathrm{~g} \mathrm{dw})$ and $\mathrm{n}-$ hexane $(186.1 \pm 0.3 \mathrm{mg} / 100 \mathrm{~g} \mathrm{dw})$.

In summary, the efficiency of HAE $E$ extraction from different mushroom bio-residues was evaluated using RSM in a CCCD with five level values per variable. This multivariable fitting provides a strong solution to minimise the experimental errors using a short number of trials, while optimising the variable conditions assisted by empirical mathematical models, which predict the maximum extraction yield (Vieira et al., 2017).

\subsection{Mathematical models derived from RSM (CCCD) using two defined variables and statistical assessment}

Before optimisation, the compounds present in the extracts were analysed by HPLC-UV; E, one of the main sterols compounds present in edible mushrooms and the major sterol present in its hyphal membranes was screened using HPLC-UV. The HAE results for the three tested mushroom bioresidues are shown in Table 1. To further analyse the obtained experimental values, a polynomial model including linear, quadratic, and interactive effects was applied. By fitting the second-order polynomial model (Eq. (1)) to the obtained experimental responses, the parametric values were estimated and presented in Table 2 . Those coefficients, which showed confidence interval values of $\alpha=0.05$ higher than the parameter value was consider as non-significant (ns) and were not used for model development.

\subsection{Response patterns derived from the RSM model}

As shown in Table 2, apart from POR-Y $1(\approx 79 \%)$ and ACR$\mathrm{Y}_{2}(\approx 77 \%), 80 \%$ of all the other responses $(\mathrm{Y})$ for the three 
Table 1 - Experimental RSM results for the optimisation of the two independent variables involved $\left(\mathrm{X}_{1}\right.$ and $\left.\mathrm{X}_{2}\right)$ in the extraction of $E$ from three different mushroom bio-residues of Pleurotus eryngii (PER), Agrocybe cylindraceae (ACR) and Pleurotus ostreatus (POR) species. Three response values were assessed ( $Y_{1}$, yield in \%; $Y_{2}, \mathrm{mg} E / g$ R; and $Y_{3}$ mg E/100 g M dw). Natural values, variables, and their ranges are displayed.

\begin{tabular}{|c|c|c|c|c|c|c|c|c|c|c|}
\hline \multicolumn{2}{|c|}{ Experimental design } & \multicolumn{9}{|c|}{ Experimental responses } \\
\hline \multirow[t]{2}{*}{$X_{1}(t, \min )$} & \multirow[t]{2}{*}{$\mathrm{X}_{2}\left(\mathrm{~T},{ }^{\circ} \mathrm{C}\right)$} & \multicolumn{3}{|c|}{ Pleurotus eryngii (PER) } & \multicolumn{3}{|c|}{ Agrocybe cylindraceae (ACR) } & \multicolumn{3}{|c|}{ Pleurotus ostreatus (POR) } \\
\hline & & $Y_{1}$ & $Y_{2}$ & $Y_{3}$ & $Y_{1}$ & $Y_{2}$ & $Y_{3}$ & $\mathrm{Y}_{1}$ & $Y_{2}$ & $Y_{3}$ \\
\hline$-1(30.5)$ & $-1(38.8)$ & 6.14 & 29.65 & 182.04 & 4.69 & 47.85 & 224.62 & 5.40 & 14.08 & 76.07 \\
\hline$-1(30.5)$ & $1(81.2)$ & 9.65 & 17.58 & 169.68 & 7.78 & 46.13 & 359.00 & 11.60 & 22.93 & 265.87 \\
\hline $1(129.5)$ & $-1(38.8)$ & 6.93 & 29.70 & 205.88 & 2.43 & 58.10 & 140.91 & 6.03 & 11.35 & 68.48 \\
\hline $1(129.5)$ & $1(81.2)$ & 13.28 & 13.00 & 172.62 & 7.93 & 41.48 & 329.04 & 7.42 & 25.15 & 186.66 \\
\hline$-1.41(10)$ & $0(60)$ & 6.18 & 17.90 & 110.61 & 5.31 & 58.20 & 308.92 & 10.13 & 22.33 & 226.19 \\
\hline $1.41(150)$ & $0(60)$ & 8.28 & 22.23 & 184.10 & 6.73 & 45.15 & 304.00 & 7.52 & 10.70 & 80.52 \\
\hline $0(80)$ & $-1.41(30)$ & 5.96 & 25.58 & 152.34 & 4.50 & 59.80 & 269.20 & 4.53 & 46.23 & 209.63 \\
\hline $0(80)$ & $1.41(90)$ & 16.89 & 10.65 & 179.85 & 7.50 & 40.33 & 302.27 & 10.53 & 21.25 & 223.78 \\
\hline$-1.41(10)$ & $-1.41(30)$ & 5.13 & 30.40 & 156.04 & 3.94 & 60.23 & 237.52 & 3.93 & 48.88 & 191.92 \\
\hline$-1.41(10)$ & $1.41(90)$ & 13.05 & 13.05 & 170.27 & 7.71 & 42.60 & 328.61 & 11.74 & 23.95 & 281.19 \\
\hline $1.41(150)$ & $-1.41(30)$ & 5.94 & 32.30 & 191.76 & 6.99 & 67.08 & 468.86 & 5.42 & 42.55 & 230.63 \\
\hline $1.41(150)$ & $1.41(90)$ & 12.19 & 16.13 & 196.61 & 8.04 & 41.83 & 336.13 & 14.75 & 13.50 & 199.16 \\
\hline $0(80)$ & $0(60)$ & 10.33 & 19.03 & 196.57 & 6.11 & 52.80 & 322.76 & 9.00 & 30.08 & 270.63 \\
\hline $0(80)$ & $0(60)$ & 11.41 & 15.25 & 173.96 & 5.92 & 51.63 & 305.48 & 8.46 & 34.00 & 287.62 \\
\hline $0(80)$ & $0(60)$ & 11.38 & 15.78 & 179.54 & 5.78 & 51.10 & 295.49 & 8.65 & 31.10 & 269.00 \\
\hline $0(80)$ & $0(60)$ & 11.13 & 18.25 & 203.18 & 5.95 & 47.33 & 281.43 & 8.85 & 32.43 & 287.02 \\
\hline
\end{tabular}

Table 2 - The statistical details and parametric results of the second-order polynomial equation of Eq. (1) for the three mushroom bio-residues (Pleurotus eryngii (PER), Agrocybe cylindraceae (ACR), and Pleurotus ostreatus (POR)) species are presented. The coded values have statistical significance at $\alpha=0.05$.

\begin{tabular}{|c|c|c|c|c|c|c|c|}
\hline & $b_{0}$ & $b_{1}(t)$ & $b_{2}(T)$ & $b_{11}\left(t^{2}\right)$ & $b_{22}\left(T^{2}\right)$ & $b_{12}(t T)$ & $R^{2}$ \\
\hline \multicolumn{8}{|c|}{$Y_{1}$} \\
\hline PER & $9.25 \pm 0.61$ & $0.53 \pm 0.36$ & $2.54 \pm 0.35$ & $-1.10 \pm 0.45$ & $0.33 \pm 0.30$ & ns & 0.8308 \\
\hline$A C R$ & $5.68 \pm 0.45$ & $0.25 \pm 0.07$ & $1.23 \pm 0.26$ & $0.20 \pm 0.17$ & $0.19 \pm 0.15$ & $-0.15 \pm 0.06$ & 0.8823 \\
\hline POR & $8.32 \pm 0.63$ & ns & $2.52 \pm 0.37$ & $0.33 \pm 0.17$ & $-0.27 \pm 0.16$ & ns & 0.7912 \\
\hline \multicolumn{8}{|c|}{$\mathrm{Y}_{2}$} \\
\hline PER & $37.79 \pm 2.01$ & ns & $-9.83 \pm 1.32$ & $3.41 \pm 1.56$ & ns & $-1.12 \pm 0.58$ & 0.8308 \\
\hline$A C R$ & $50.70 \pm 1.06$ & $0.35 \pm 0.26$ & $-6.66 \pm 1.05$ & ns & ns & $-1.51 \pm 0.94$ & 0.7739 \\
\hline POR & $26.87 \pm 4.37$ & $-2.45 \pm 1.58$ & $-5.56 \pm 2.56$ & $-4.22 \pm 3.28$ & $4.31 \pm .22$ & ns & 0.8168 \\
\hline \multicolumn{8}{|c|}{$\mathrm{Y}_{3}$} \\
\hline PER & $336.23 \pm 12.55$ & $17.19 \pm 8.35$ & $16.26 \pm 8.16$ & ns & $-17.71 \pm 9.46$ & $-10.19 \pm 7.30$ & 0.8470 \\
\hline$A C R$ & $279.57 \pm 2.97$ & $14.77 \pm 5.14$ & $19.40 \pm 3.64$ & $14.05 \pm 6.65$ & $6.59 \pm 2.13$ & $-19.69 \pm 4.71$ & 0.8890 \\
\hline POR & $239.15 \pm 25.03$ & $-20.23 \pm 4.79$ & $25.61 \pm 7.46$ & $-28.88 \pm 5.95$ & ns & $-15.65 \pm 5.72$ & 0.8825 \\
\hline
\end{tabular}

ns: non-significant coefficient; $R^{2}$ : correlation coefficient.

mushroom bio-residues were successfully explained by temperature and time collectively. The parametric coefficients (Table 2) obtained after the mathematical model application provide specific information of the impact of the two independent variables and their antagonist/synergetic implication in the final responses. The linear effect played an important role in all the three mushroom bio-residues extractions. Apart from PER-Y $Y_{2}$ and POR-Y $Y_{1}$ responses, the linear effect $t$ was significant in all the other cases, being PER-Y $Y_{3}$ the response where thad the biggest positive impact and POR-Y $Y_{3}$ the biggest negative impact in the final responses. Contrarily, the linear effect of $\mathrm{T}$ was significant in all the three responses of the different mushroom bio-residues, where POR-Y 3 showed the highest positive $(25.61 \pm 7.46)$ and PER $-Y_{2}$ the most negative $(-9.83 \pm 1.32)$ impact. The presence of positive quadratic effects implies that almost all responses showed non-linear patterns, which is directly related with the nature of the chosen variables. In derived mathematical models, responses are studied separately and the determination of the optimum independent variables is not possible. Interactive parametric values can act as a control for multivariable analysis (RSM) to properly determine the best extraction conditions. Regard- ing tT interactive effect in $Y_{1}$ response (\% yield), PER and POR mushroom bio-residues showed non-significant interaction, contrarily to ACR, where this interaction had a negative impact in the final response $(-0.15 \pm 0.006)$. For $\mathrm{Y}_{2}(\mathrm{mg} \mathrm{E} / \mathrm{g} \mathrm{R})$, $\mathrm{tT}$ had a negative impact for PER and ACR final response $(-1.12 \pm 0.58$ and $-1.51 \pm 0.94$, respectively), and a non-significant to POR bio-residues final response. Regarding $\mathrm{Y}_{3}(\mathrm{mg} \mathrm{E} / 100 \mathrm{~g} \mathrm{M} \mathrm{dw}$ ), tT interaction had a negative impact in all the responses of the different mushroom bio-residues. In conclusion, a nonlinear multivariable analysis was needed in order to fully fit the experimental results.

Although with longer extraction periods (150 min), PER and ACR presented similar E yield to POR (65.6 min), 60.75, 63.62, and $43.72 \mathrm{mg} \mathrm{E} / \mathrm{g} R$, respectively. PER-Y 2 graphical representation highlights that at $30^{\circ} \mathrm{C}$, the optimal response can be obtained with both short and long periods of extraction. The linear parametric values of the second-order polynomial equation for time and temperature of PER- $Y_{2}$, non-significant and $-9.83 \pm 1.32$, respectively, show the negative impact that temperature has in $\mathrm{Y}_{2}$ response. Contrarily, the quadratic effect of time $\left(t^{2}: 3.41 \pm 1.56\right)$ has a positive impact in the final response and, together with the non-significant effect 
of $\mathrm{T}^{2}$, confirms that time is the main optimal independent variable to be considered for an optimal PER- $Y_{2}$ response. Therefore, the long extraction period required for PER-Y, $150 \mathrm{~min}$, is not suitable for industrial applications. In contrast to PER-Y2, POR optimal time predicted by the model is $43.72 \mathrm{~min}$, this result is confirmed by the negative effect of the linear parametric values, $t(-2.45 \pm 1.58)$ and $T(-5.56 \pm 2.56)$, together with the positive quadratic effect of temperature $\left(T^{2}: 4.31 \pm 3.22\right)$ and the negative effect of $t^{2}(-4.22 \pm 3.28)$. These values confirm that the quadratic effect of temperature $\left(\mathrm{T}^{2}\right)$ is the main optimal independent variable for a $\mathrm{Y}_{2}$-POR optimum response, being more appropriate than PER for industrial purposes. POR-Y $\mathrm{Y}_{3}$ extraction led to the best result, $290.90 \mathrm{mg} E / 100 \mathrm{~g} \mathrm{M}$ dw. Although POR-Y 3 did not present the highest content of $E$ extracted from the three mushroom bio-residues (ACR: $366.80 \mathrm{mg} \mathrm{E} / 100 \mathrm{~g} \mathrm{M} \mathrm{dw}$ ), in terms of $E$ purity, time and energy reductions, POR-Y $Y_{3}$ optimal conditions were considered the most favourable. PER-Y $Y_{3}$ graphical representation and independent variables show a tendency to long extraction periods independently of the temperature applied, condition not optimal for industrial purposes, where shorter periods for extraction are the ideal. Similarly, ACR-Y 3 increases together with time and temperature. The optimum independent variables, time and temperature, predicted by the model for $\mathrm{POR}-\mathrm{Y}_{3}$ are $43.7 \mathrm{~min}$ at $90^{\circ} \mathrm{C}$. In conformity with these values, Fig. 3 arrow tendency also shows that to obtain POR-Y $Y_{3}$ optimal response, high temperatures and low extraction time are the optimal solution. These results, together with the linear parametric values of the second-order polynomial equation for time and temperature, $-20.23 \pm 4.79$ and $25.61 \pm 7.46$, respectively, show the negative impact of time and the great influence of temperature in $Y_{3}$ response. The quadratic effect of time $\left(t^{2}:-28.88 \pm 5.95\right)$ has a negative impact in the final $Y_{3}$ response and, together with the negative interactive effect ( $t T:-15.65 \pm 5.72)$, and the non-significance of the quadratic effect of temperature $\left(T^{2}\right)$ confirms that temperature is the main optimal independent variable to be considered for POR-Y $Y_{3}$ optimal response. For both responses $\mathrm{Y}_{2}$ an $\mathrm{Y}_{3}$, POR was the most industrially appealing bio-residue when comparing the three mushrooms.

Fig. 1 shows the HAE results for $Y_{1}$ response, expressed as extraction yield \%. Fig. 1 is divided in three units, each one corresponding to the different results obtained with the three mushroom bio-residues. Additionally, each unit is divided into four sections (A to D). Section A shows the 3D surface plots for the two possible variable combinations. Section $B$ is a two-dimensional representation of the fitting of Eq. (1) to the experimental data. The binary combinations between variables are presented when the excluded variable is positioned at the optimum of the experimental domain. Section $C$ illustrates the capability to predict the obtained results and the residual distribution as a function of each considered variables. Taking the distribution of the residuals presented in Fig. 1 as an example of all the achieved responses, it can be perceived that they are arbitrarily around zero and no groups of values, or auto correlations, were observed.

For PER-Y $Y_{1}$ response, and as can be observed on the first three dimensional plot, the extraction yield percentage rises as temperature increases. When compared to $t, T$ is the more relevant of the two independent variables, this significance is also clear through the observation of the linear parametric values of the second-order polynomial equation presented on Table 2, $2.54 \pm 0.35$ and $0.53 \pm 0.36$, respectively. Section $C$ shows a line of almost perfect fitting, a consequence of the ability of model to describe the experimental data reasonably well. The residuals are the difference between the predicted and the experimental values for the two analysed independent variables ( $t$ and $T$ ) and as can be observed, the distribution is low, with minimum autocorrelation, no variables missing from the model.

Regarding ACR and POR-Y $Y_{1}$ responses, similarly to PER$Y_{1}, T$ is the more relevant of the two independent variables. For both responses, this was clearly observed through the analysis of the parametric values of the second-order polynomial equation presented on Table 2, where the model gives small significance to $t$ in ACR $(0.25 \pm 0.07)$ final response and non-significance for POR. In both cases, subunit $C$ shows a line of almost perfect fitting and the distribution between experimental and predicted values is low, with minimum autocorrelation.

Section D shows the individual 2D responses of the three different mushroom bio-residues as a function of the defined variables for HAE extraction technique. The dots highlight the location of the optimum value. Lines and dots are generated by the theoretical second order polynomial. The properly optimised responses $\left(\mathrm{Y}_{1}, \mathrm{Y}_{2}, \mathrm{Y}_{3}\right)$ display patterns in which the amount of extracted compounds increases to an optimum value and then decreases as a function of each of the assessed independent variables. Therefore, an absolute optimum can be found at one single point, allowing computing and consequently leading to the absolute maximum. For instance, all responses derived from the HAE produced clear optimal responses for all variables, where few responses showed tendencies towards an absolute optimum.

\subsection{Individual and global numerical optimal conditions that maximises the extraction}

The optimal absolute or relative conditions that maximise the individual and global responses criteria presented in Figs. 1 and 2 (Sections A, B, and D), and Fig. 3 are displayed numerically in Table 3 and graphically in Figs. 1 and 2 section D. These values were obtained through a simple procedure by inserting restrictions to the experimental ranges. Part A of Table 3 shows the individual optimal conditions regarding $\mathrm{HAE}$ for all the $E$ content responses $\left(Y_{2}\right.$ and $\left.Y_{3}\right)$ and \% of obtained extracts $\left(\mathrm{Y}_{3}\right)$.

The most expressive $Y_{1}$ response regarding the three mushroom bio-residues was $Y_{1}$-PER (13.56\%), followed by POR (12.01\%) and ACR (8.24\%). For PER-Y 1 individual response, the optimum independent variables were $91.9 \mathrm{~min}$ at $90^{\circ} \mathrm{C}$. When analysing the graphical representations A and B of Fig. 1, regarding PER mushroom bio-residues, it is possible conclude that using the same temperature $\left(90^{\circ} \mathrm{C}\right)$, and reducing the extraction time $( \pm 50 \mathrm{~min})$, the \% yield of total extract is approximately the same. In Fig. 3, this conclusion becomes even more evident, the arrows show the \% yield tendency, and in both cases, it points to less time ( $\pm 50 \mathrm{~min})$ and higher temperatures $\left(90^{\circ} \mathrm{C}\right)$. Though the optimal PER-Y $Y_{1}$ variables predicted by the model point to a long extraction time, analysing the graphical representations and the parametric values of the secondary polynomial equation, it is possible to conclude that a longer exposure will not make a massive difference in the extraction \% yield. ACR- $Y_{1}$ shows exactly the same pattern as PER, although the model predicts long extraction time. When analysing the graphical representations, it is 


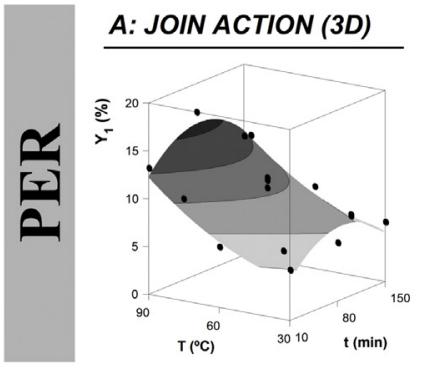

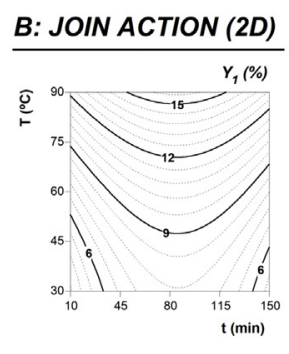

\section{C: STATISTICAL ANALYSIS}
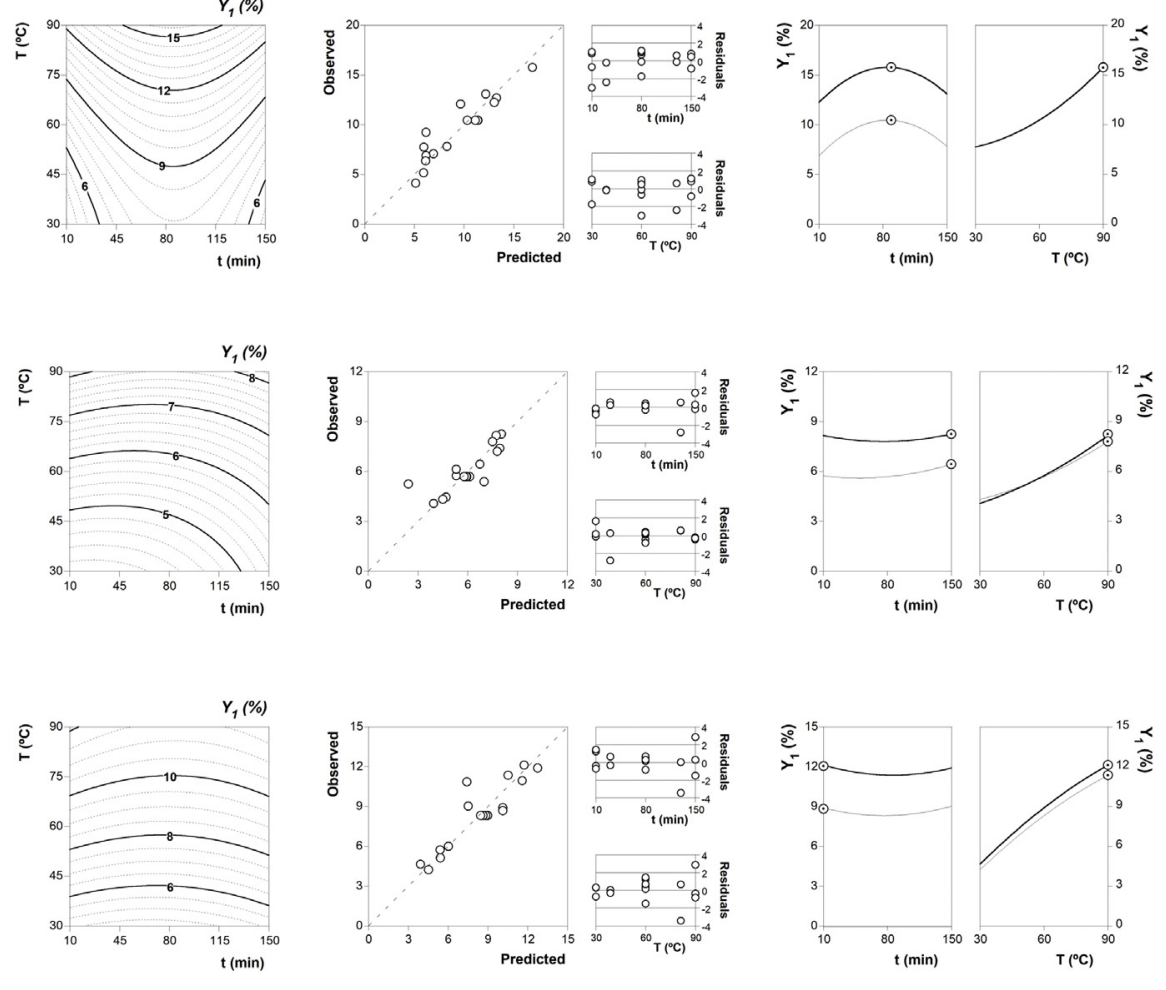

\section{D: OPTIMAL VALUES}
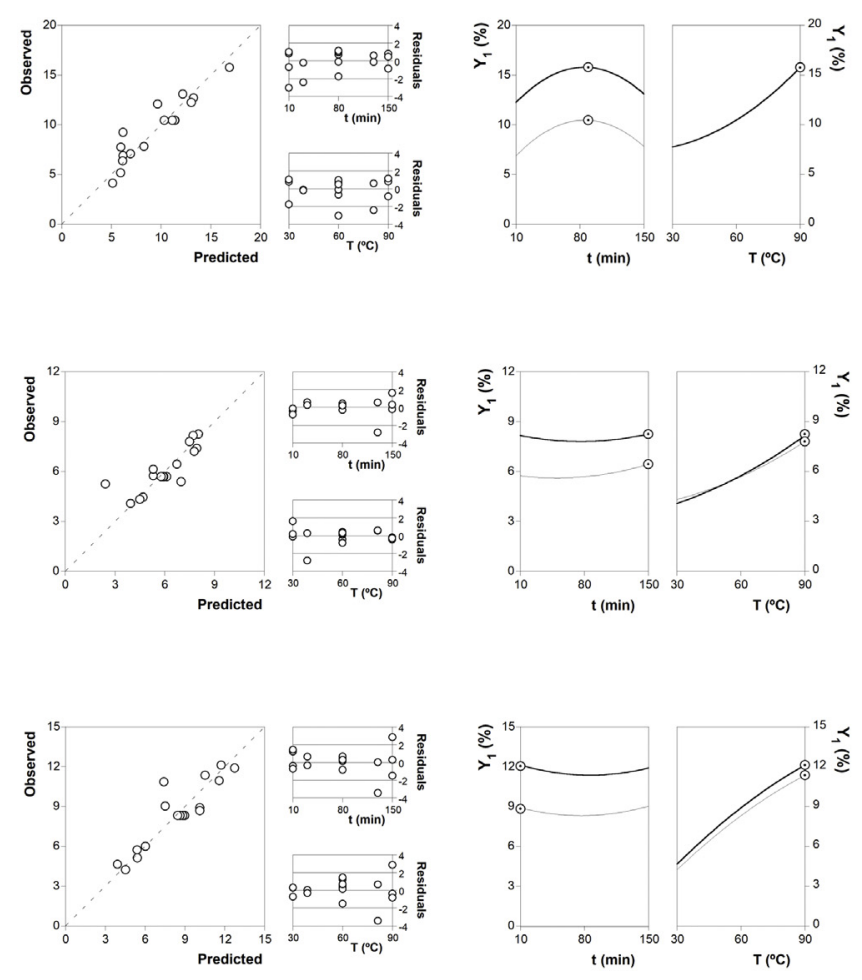

Fig. 1 - Graphical results in terms of response value format $Y_{1}(\%)$ for three different mushroom bio-residues of Pleurotus eryngii (PER), Agrocybe cylindraceae (ACR) and Pleurotus ostreatus (POR) species. Section A: Points (O) represent the experimental results displayed in Table 1 and the net surface denotes the theoretical 3D response surface predicted by the model as a function of each independent variable. Section B: Represents a 2D fitting of the experimental results. Section C: Represents the statistical description using two graphical criteria: the ability to simulate the changes of the response and the residual distribution as a function of each of the variable. Section $D$ : The dots $(\odot)$ represent the location of the optimum value generated by Eq. (1).

\begin{tabular}{|c|c|c|c|c|c|}
\hline \multirow[t]{2}{*}{ Criteria } & & \multicolumn{2}{|c|}{ Optimal variable conditions } & \multicolumn{2}{|c|}{ Optimum response } \\
\hline & & $x_{1}: t$ (min) & $\mathrm{X}_{2}: \mathrm{T}\left({ }^{\circ} \mathrm{C}\right)$ & & \\
\hline \multicolumn{6}{|c|}{ (A) Individual optimal conditions } \\
\hline & $\mathrm{Y}_{1}$ & 91.9 & 90.0 & 13.56 & $\%$ \\
\hline \multirow[t]{3}{*}{ PER } & $\mathrm{Y}_{2}$ & 150.0 & 30.0 & 60.75 & $\mathrm{mg} \mathrm{E} / \mathrm{g} \mathrm{R}$ \\
\hline & $\mathrm{Y}_{3}$ & 150.0 & 61.1 & 360.60 & $\mathrm{mg} \mathrm{E} / 100 \mathrm{~g} \mathrm{M} \mathrm{dw}$ \\
\hline & $\mathrm{Y}_{1}$ & 150.0 & 90.0 & 8.24 & $\%$ \\
\hline \multirow[t]{3}{*}{ ACR } & $\mathrm{Y}_{2}$ & 150.0 & 30.0 & 63.62 & $\mathrm{mg} \mathrm{E} / \mathrm{g} \mathrm{R}$ \\
\hline & $\mathrm{Y}_{3}$ & 10.0 & 90.0 & 366.80 & $\mathrm{mg} \mathrm{E} / 100 \mathrm{~g} \mathrm{M} \mathrm{dw}$ \\
\hline & $\mathrm{Y}_{1}$ & 10.0 & 90.0 & 12.01 & $\%$ \\
\hline \multirow[t]{4}{*}{ POR } & $\mathrm{Y}_{2}$ & 65.6 & 30.0 & 43.72 & mg E/g R \\
\hline & $\mathrm{Y}_{3}$ & 43.7 & 90.0 & 290.90 & $\mathrm{mg} \mathrm{E} / 100 \mathrm{~g} \mathrm{M} \mathrm{dw}$ \\
\hline & & & al optimal condit & & \\
\hline & $\mathrm{Y}_{1}$ & & & 8.02 & $\%$ \\
\hline \multirow[t]{3}{*}{ PER } & $\mathrm{Y}_{2}$ & 150.0 & 61.8 & 43.63 & $\mathrm{mg} \mathrm{E} / \mathrm{g} \mathrm{R}$ \\
\hline & $\mathrm{Y}_{3}$ & & & 360.58 & $\mathrm{mg} \mathrm{E} / 100 \mathrm{~g} \mathrm{M} \mathrm{dw}$ \\
\hline & $\mathrm{Y}_{1}$ & & & 8.24 & $\%$ \\
\hline \multirow[t]{3}{*}{ ACR } & $\mathrm{Y}_{2}$ & 150.0 & 90.0 & 38.76 & $\mathrm{mg} \mathrm{E} / \mathrm{g} \mathrm{R}$ \\
\hline & $\mathrm{Y}_{3}$ & & & 329.79 & $\mathrm{mg} \mathrm{E} / 100 \mathrm{~g} \mathrm{M} \mathrm{dw}$ \\
\hline & $\mathrm{Y}_{1}$ & & & 11.47 & $\%$ \\
\hline \multirow[t]{2}{*}{ POR } & $\mathrm{Y}_{2}$ & 50.4 & 90.0 & 27.58 & $\mathrm{mg} \mathrm{E} / \mathrm{g} \mathrm{R}$ \\
\hline & $\mathrm{Y}_{3}$ & & & 290.38 & $\mathrm{mg} \mathrm{E} / 100 \mathrm{~g} \mathrm{M} \mathrm{dw}$ \\
\hline
\end{tabular}

possible to conclude that a reduction in extraction time will not drastically interfere in the final response. For POR-Y 1 , the optimum independent variables were $10 \mathrm{~min}$ at $90^{\circ} \mathrm{C}$, what can be confirmed through the analysis of the graphical representations of the model for this mushroom bio-residue and its corresponding parametric values presented on Table 2. 

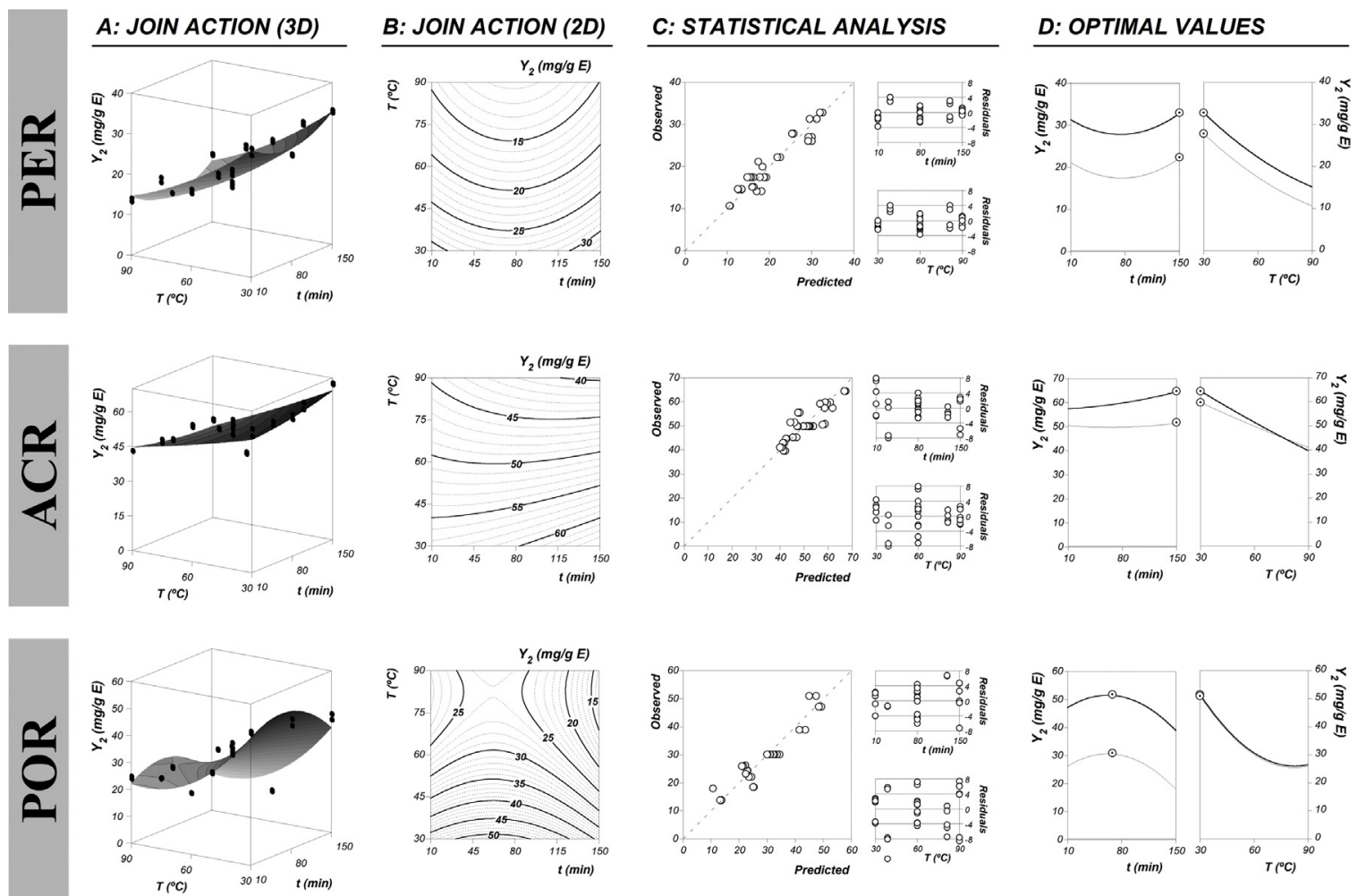

Fig. 2 - Graphical results in terms of response value format $\mathrm{Y}_{2}(\mathrm{mg} \mathrm{E} / \mathrm{g} \mathrm{R})$ for three different mushroom bio-residues of Pleurotus eryngii (PER), Agrocybe cylindraceae (ACR) and Pleurotus ostreatus (POR) species. Section A: Points ( $\bullet$ ) represent the experimental results displayed in Table 1 and the net surface denotes the theoretical 3D response surface predicted by the model as a function of each independent variable. Section B: Represents a 2D fitting of the experimental results. Section C: Represents the statistical description using two graphical criteria: the ability to simulate the changes of the response and the residual distribution as a function of each of the variable. Section $D$ : The dots $(\odot)$ ) represent the location of the optimum value generated by Eq. (1).

Concerning the $\mathrm{mg}$ of $\mathrm{E} / \mathrm{g} \mathrm{R}$, the best $\mathrm{Y}_{2}$ response was obtained for ACR (63.62 mg E/g R), followed by PER $(60.75 \mathrm{mg}$ $\mathrm{E} / \mathrm{g} \mathrm{R}$ ) and POR (43.72 $\mathrm{mg} \mathrm{E} / \mathrm{g} \mathrm{R}$ ). For the three mushroom bioresidues, the predicted optimum independent variables for $\mathrm{Y}_{2}$ response are in accordance with all the graphical representations (Sections A and B of Figs. 1 and 3) and the correspondent parametric values (Table 2). Although with longer extraction periods (150 min), PER and ACR have similar E yield to POR (65.6 min), 60.75, 63.62, and $43.72 \mathrm{mg} \mathrm{E} / \mathrm{g} \mathrm{R}$, respectively.

Finally, for $\mathrm{Y}_{3}$; although very similar, the highest predicted response was presented by ACR ( $366.80 \mathrm{mg}$ E/100 g M dw), followed by PER (360.60 mg E/100 g M dw) and POR (290.90 mg $\mathrm{E} / 100 \mathrm{~g} \mathrm{M} \mathrm{dw})$. Although PER-Y $\mathrm{Y}_{3}$ optimum response presented the longer extraction time $(150 \mathrm{~min})$, the final $E$ yield, $\mathrm{mg}$ $\mathrm{E} / 100 \mathrm{~g} \mathrm{M} \mathrm{dw}$, was very similar to the other two mushroom bio-residues, ACR (10 min) and POR (43.7 min), 366.80 and $290.90 \mathrm{mg}$ E/100 g M dw, respectively. Despite the predicted optimum independent variables for $\mathrm{PER}$ pointed a long extraction time, $150 \mathrm{~min}$, at a high temperature $\left(61.1^{\circ} \mathrm{C}\right)$, its graphical representation (Fig. 3) shows a tendency (arrows) to long extraction periods independently of the temperature applied, confirmed by the negative effect of the quadratic value of temperature $\left(T^{2}:-17.71 \pm 9.46\right)$. Even though the optimum predicted value for $\mathrm{ACR}-\mathrm{Y}_{3}$ response was $10 \mathrm{~min}$, Fig. 3 arrow also shows that $E$ response $(\mathrm{mg})$ in $100 \mathrm{~g}$ of bio-residues is directly proportional to the independent variables. $Y_{3}$ response will follow the same tendency as time and temperature increase.
The optimum independent variables, time and temperature, predicted by the model for POR are $43.7 \mathrm{~min}$ at $90^{\circ} \mathrm{C}$. Accordingly, Fig. 3 arrow tendency and the linear parametric values of the second-order polynomial equation for $\mathrm{T}(25.61 \pm 7.46)$ and $t(-20.23 \pm 4.79)$, confirmed that for an POR-Y $Y_{3}$ optimum response, high temperatures and low extraction time are the optimal solution.

The combined information of the three responses behaviour for all the mushroom bio-residues was defined in global terms. The global optimum results for the three mushrooms bio-residues are presented in Table 3, section $B$. In global terms, for PER and ACR, a long extraction time (150 min) and high temperatures, 61.8 and $90.0^{\circ} \mathrm{C}$, respectively, were the optimum values predicted by the model for an optimal equilibrium between the three responses. Similarly, to the other two mushroom bio-residues, a high extraction temperature $\left(90.0^{\circ} \mathrm{C}\right)$ was required to attain POR optimal equilibrium between the three responses contrarily to a shorter extraction time, $50.4 \mathrm{~min}$.

Overall, HAE is a powerful extraction method that has proved to be efficient in terms of $E$ extraction yield and extract purity. Ethanol proved to be a good solvent, what is in agreement with the results obtained during a previous study, where the performance of different environmentally friendly solvents for E extraction was compared. The effect of liquid-to-solid ratio on $E$ yield has been well reported, with no significant impact on $E$ extraction yield. Thus, an interme- 

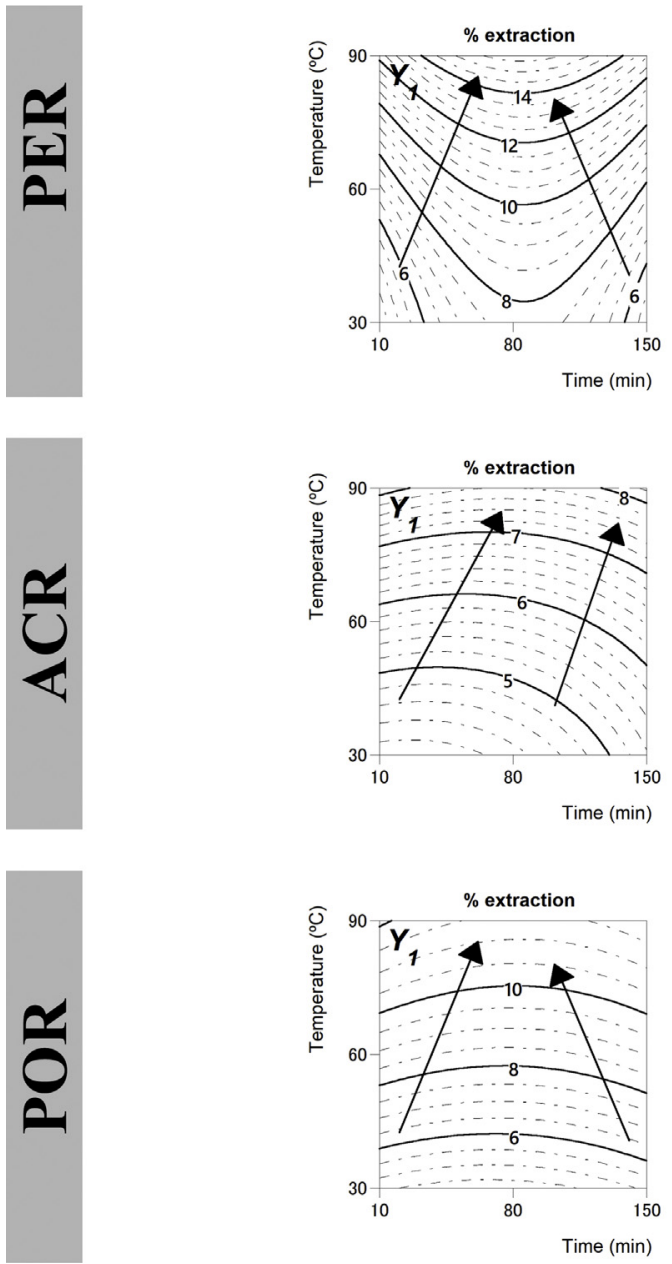
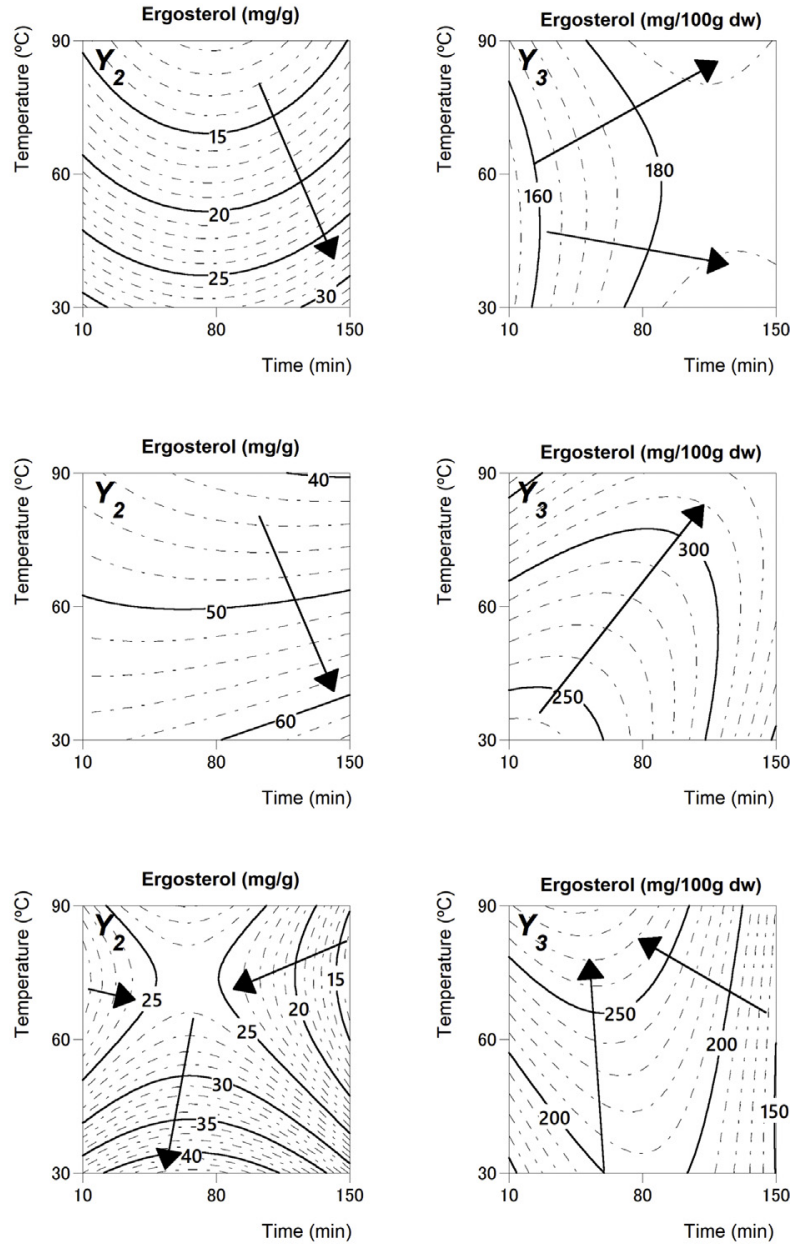

Fig. 3 - Graphical summary of the RSM results for the optimisation of the two main variables involved ( $X_{1}$ and $\left.X_{2}\right)$ in the extraction of $E$ from three mushroom bio-residues of Pleurotus eryngii (PER), Agrocybe cylindraceae (ACR) and Pleurotus ostreatus (POR) species for the three responses assessed ( $Y_{1}$, yield in \%; $Y_{2}, \mathrm{mg} E / g \mathrm{R} ;$ and $\mathrm{Y}_{3} \mathrm{mg} \mathrm{E} / 100 \mathrm{~g} \mathrm{M} \mathrm{dw).}$

diate liquid-to-solid ratio of $30 \mathrm{~g} / \mathrm{L}$ was used in all the present study experiments.

\section{Conclusions}

RSM was successfully employed to optimise $E$ extraction and to find the optimal independent variables. $Y_{2}$ and $Y_{3}$ were considered the guiding responses in terms of optimisation for industrial transference. $Y_{2}$ optimal independent variables estimated by the model are in accordance with all the graphical bio-residues representations. The extraction process optimisation proved to be a viable option for obtaining ergosterol rich extracts from mushroom bio-residues and bearing in mind the results presented herein, large scale heat-assisted extraction processes can be designed for ergosterol extraction and an opportunity to develop the circular and sustainable bioeconomy in mushroom value chain.

\section{Conflict of interest}

The authors declare that there is no conflict of interest.

\section{Acknowledgements}

The authors are grateful to the Foundation for Science and Technology (FCT, Portugal) for financial support through national funds FCT/MCTES to CIMO (UIDB/00690/2020); this work was funded by FEDER through POCI, within the scope of project MicoBioExtract (POCI-01-0247-FEDER-033939). L. Barros also thanks the national funding by FCT, P.I., through the institutional scientific employment program-contract for their contracts. To MICINN for the financial support for the Ramón\&Cajal researcher of M.A. Prieto.

\section{References}

Albuquerque, B.R., Prieto, M.A., Barreiro, M.F., Rodrigues, A., Curran, T.P., Barros, L., Ferreira, I.C.F.R., 2016. Catechin-based extract optimization obtained from Arbutus unedo L. fruits using maceration/microwave/ultrasound extraction techniques. Ind. Crops Prod. 95, 404-415.

Barreira, J.C.M., Oliveira, M.B.P.P., Ferreira, I.C.F.R., 2014. Development of a novel methodology for the analysis of ergosterol in mushrooms. Food Anal. Methods 7, 217-223, http://dx.doi.org/10.1007/s12161-013-9621-9.

Boin, E., Nunes, J., 2018. Mushroom consumption behavior and influencing factors in a sample of the Portuguese population. J. Int. Food Agribus. Mark. 30, 35-48, http://dx.doi.org/10.1080/08974438.2017.1382420.

Cásedas, G., Les, F., Gómez-Serranillos, M.P., Smith, C., López, V., 2017. Anthocyanin profile, antioxidant activity and enzyme inhibiting properties of blueberry and cranberry juices: a comparative study. Food Funct. 8, 4187-4193, http://dx.doi.org/10.1039/C7FO01205E.

Chemat, F., Rombaut, N., Meullemiestre, A., Turk, M., Perino, S., Fabiano-Tixier, A.-S., Abert-Vian, M., 2017. Review of green food processing techniques, preservation, transformation, 
and extraction. Innov. Food Sci. Emerg. Technol. 41, 357-377, http://dx.doi.org/10.1016/J.IFSET.2017.04.016.

Corrêa, R.C.G., Barros, L., Fernandes, Â., Sokovic, M., Bracht, A., Peralta, R.M., Ferreira, I.C.F.R., 2018. A natural food ingredient based on ergosterol: optimization of the extraction from Agaricus blazei, evaluation of bioactive properties and incorporation in yogurts. Food Funct. 9, 1465-1474, http://dx.doi.org/10.1039/c7fo02007d.

Gil-Ramírez, A., Aldars-García, L., Palanisamy, M., Jiverdeanu, R.M., Ruiz-Rodríguez, A., Marín, F.R., Reglero, G., Soler-Rivas, C., 2013. Sterol enriched fractions obtained from Agaricus bisporus fruiting bodies and by-products by compressed fluid technologies (PLE and SFE). Innov. Food Sci. Emerg. Technol. 18, 101-107, http://dx.doi.org/10.1016/j.ifset.2013.01.007.

Gil-Ramírez, A., Caz, V., Martin-Hernandez, R., Marín, F.R., Largo, C., Rodríguez-Casado, A., Tabernero, M., Ruiz-Rodríguez, A., Reglero, G., Soler-Rivas, C., 2016. Modulation of cholesterol-related gene expression by ergosterol and ergosterol-enriched extracts obtained from Agaricus bisporus. Eur. J. Nutr. 55, 1041-1057, http://dx.doi.org/10.1007/s00394-015-0918-x.

Grimm, D., Wösten, H.A.B., 2018. Mushroom cultivation in the circular economy. Appl. Microbiol. Biotechnol. 102, 7795-7803, http://dx.doi.org/10.1007/s00253-018-9226-8.

He, L., Shi, W., Liu, X., Zhao, X., Zhang, Z., 2018. Anticancer action and mechanism of ergosterol peroxide from Paecilomyces cicadae fermentation broth. Int. J. Mol. Sci. 19, http://dx.doi.org/10.3390/ijms19123935.

Heleno, S.A., Diz, P., Prieto, M.A., Barros, L., Rodrigues, A., Barreiro, M.F., Ferreira, I.C.F.R., 2016a. Optimization of ultrasound-assisted extraction to obtain mycosterols from Agaricus bisporus L. by response surface methodology and comparison with conventional Soxhlet extraction. Food Chem. 197, 1054-1063.

Heleno, S.A., Prieto, M.A., Barros, L., Rodrigues, A.A., Barreiro, M.F., Ferreira, I.C.F.R., 2016b. Optimization of microwave-assisted extraction of ergosterol from Agaricus bisporus L. by-products using response surface methodology. Food Bioprod. Process. 100, 25-35.

Kalač, P., 2009. Chemical composition and nutritional value of European species of wild growing mushrooms: a review. Food Chem. 113, 9-16, http://dx.doi.org/10.1016/j.foodchem.2008.07.077.

Kang, J.H., Jang, J.E., Mishra, S.K., Lee, H.J., Nho, C.W., Shin, D., Jin M., Kim, M.K., Choi, C., Oh, S.H., 2015. Ergosterol peroxide from Chaga mushroom (Inonotus obliquus) exhibits anti-cancer activity by down-regulation of the $\beta$-catenin pathway pathway in colorectal cancer. J. Ethnopharmacol. 173, 303-312, http://dx.doi.org/10.1016/j.jep.2015.07.030.

Khadhraoui, B., Turk, M., Fabiano-Tixier, A.S., Petitcolas, E., Robinet, P., Imbert, R., Maâtaoui, M., El Chemat, F., 2018. Histo-cytochemistry and scanning electron microscopy for studying spatial and temporal extraction of metabolites induced by ultrasound. Towards chain detexturation mechanism. Ultrason. Sonochem. 42, 482-492.

Leiva, F.J., Saenz-Díez, J.C., Martínez, E., Jiménez, E., Blanco, J., 2015. Environmental impact of Agaricus bisporus cultivation process. Eur. J. Agron. 71, 141-148, http://dx.doi.org/10.1016/j.eja.2015.09.013.

López, C.J., Caleja, C., Prieto, M.A., Barreiro, M.F., Barros, L., Ferreira, I.C.F.R., 2018. Optimization and comparison of heat and ultrasound assisted extraction techniques to obtain anthocyanin compounds from Arbutus unedo L. fruits. Food Chem. 264, 81-91,

http://dx.doi.org/10.1016/j.foodchem.2018.04.103.

Ma, L., Chen, H., Dong, P., Lu, X., 2013. Anti-inflammatory and anticancer activities of extracts and compounds from the mushroom Inonotus obliquus. Food Chem. 139, 503-508, http://dx.doi.org/10.1016/j.foodchem.2013.01.030.

Marangoni, F., Poli, A., 2010. Phytosterols and cardiovascular health. Pharmacol. Res. 61, 193-199, http://dx.doi.org/10.1016/J.PHRS.2010.01.001.
Mattila, P., Lampi, A.M., Ronkainen, R., Toivo, J., Piironen, V., 2002. Sterol and vitamin D2 contents in some wild and cultivated mushrooms. Food Chem. 76, 293-298, http://dx.doi.org/10.1016/S0308-8146(01)00275-8.

Muñiz-Márquez, D.B., Wong-Paz, J.E., Contreras-Esquivel, J.C., Rodriguez-Herrera, R., Aguilar, C.N., 2019. Extraction of phenolic compounds from Coriandrum sativum L. and Amaranthus hybridus L. by microwave technology. In: Polyphenols in Plants. Elsevier, pp. 185-190, http://dx.doi.org/10.1016/b978-0-12-813768-0.00012-8.

Pinela, J., Prieto, M.A., Barreiro, M.F., Carvalho, A.M., Oliveira, M.B.P.P., Curran, T.P., Ferreira, I.C.F.R., 2017. Valorisation of tomato wastes for development of nutrient-rich antioxidant ingredients: a sustainable approach towards the needs of the today's society. Innov. Food Sci. Emerg. Technol. 41, 160-171, http://dx.doi.org/10.1016/j.ifset.2017.02.004.

Pinela, J., Prieto, M.A., Barros, L., Maria, A., Oliveira, M.B.P.P., Saraiva, J.A., Ferreira, I.C.F.R., 2018. Cold extraction of phenolic compounds from watercress by high hydrostatic pressure: process modelling and optimization. Sep. Purif. Technol. 192, 501-512, http://dx.doi.org/10.1016/j.seppur.2017.10.007.

Research and Markets, 2018. Global Mushroom Market Size, Market Share, Application Analysis, Regional Outlook, Growth Trends, Key Players, Competitive Strategies and Forecasts, 2018 to 2026. Report ID 4620326.

Roriz, C.L., Barros, L., Prieto, M.A., Morales, P., Ferreira, I.C.F.R., 2017. Floral parts of Gomphrena globosa L. as a novel alternative source of betacyanins: optimization of the extraction using response surface methodology. Food Chem. 229, 223-234.

Royse, D.J., Baars, J., Tan, Q., 2017. Current overview of mushroom production in the world. In: Edible and Medicinal Mushrooms. John Wiley \& Sons, Ltd, Chichester, UK, pp. 5-13, http://dx.doi.org/10.1002/9781119149446.ch2.

Sarabia, L.A., Ortiz, M.C., 2009. Response surface methodology. In: Comprehensive Chemometrics. Elsevier, pp. 345-390, http://dx.doi.org/10.1016/B978-044452701-1.00083-1.

Schneider, I., Kressel, G., Meyer, A., Krings, U., Berger, R.G., Hahn, A., 2011. Lipid lowering effects of oyster mushroom (Pleurotus ostreatus) in humans. J. Funct. Foods 3, 17-24, http://dx.doi.org/10.1016/J.JFF.2010.11.004.

Tao, W., Svetlana, Z.F., Ann, D., Sams, C.E., 2004. Chitin and ChitosanValue-Added Products from Mushroom Waste., http://dx.doi.org/10.1021/JF0492565.

Taofiq, O., Corrêa, R.C.G., Barros, L., Prieto, M.A., Bracht, A., Peralta, R.M., González-paramás, A.M., Barreiro, M.F., Ferreira, I.C.F.R., 2019. A comparative study between conventional and non-conventional extraction techniques for the recovery of ergosterol from Agaricus blazei Murrill. Food Res. Int. 125, 108541, http://dx.doi.org/10.1016/j.foodres.2019.108541.

Taofiq, O., González-Paramás, A.M., Martins, A., Barreiro, M.F., Ferreira, I.C.F.R., 2016a. Mushrooms extracts and compounds in cosmetics, cosmeceuticals and nutricosmetics - a review. Ind. Crops Prod. 90, 38-48, http://dx.doi.org/10.1016/j.indcrop.2016.06.012.

Taofiq, O., Heleno, S., Calhelha, R., Alves, M., Barros, L., Barreiro, M., González-Paramás, A., Ferreira, I., 2016b. Development of mushroom-based cosmeceutical formulations with anti-inflammatory, anti-tyrosinase, antioxidant, and antibacterial properties. Molecules 21, 1372, http://dx.doi.org/10.3390/molecules21101372.

Taofiq, O., Martins, A., Barreiro, M.F., Ferreira, I.C.F.R., 2016c. Anti-inflammatory potential of mushroom extracts and isolated metabolites. Trends Food Sci. Technol. 50, 193-210, http://dx.doi.org/10.1016/j.tifs.2016.02.005.

Tintino, S.R., Oliveira-Tintino, C.D.M., Campina, F.F., Costa, M.S., Cruz, R.P., Pereira, R.L.S., Andrade, J.C., Sousa, E.O., Siqueira-Junior, J.P., Coutinho, H.D.M., Leal-Balbino, T.C., Balbino, V.Q., 2017. Cholesterol and ergosterol affect the activity of Staphylococcus aureus antibiotic efflux pumps. Microb. Pathog. 104, 133-136,

http://dx.doi.org/10.1016/j.micpath.2017.01.019. 
Valverde, M.E., Hernández-pérez, T., Paredes-lópez, O., 2015. Edible mushrooms: improving human health and promoting quality life. Int. J. Microbiol. 2015,

http://dx.doi.org/10.1155/2015/376387.
Vieira, V., Prieto, M.A., Barros, L., Coutinho, J.A.P., Ferreira, O., Ferreira, I.C.F.R., 2017. Optimization and comparison of maceration and microwave extraction systems for the production of phenolic compounds from Juglans regia L. for the valorization of walnut leaves. Ind. Crops Prod. 107, 341-352. 